\title{
Who Am I: Identity Construction of Otherness on a Social Media
}

\author{
John Wankah Foncha
}

\author{
School of Further and Continuing Education (SFCS) in the Faculty of Education of the University of Fort Hare
} jfoncha@ufh.ac.za and foncha2008@gmail.com

Doi:10.5901/mjss.2014.v5n23p1805

\section{Abstract}

Staying the same without change is a reverse of growth. To develop in one's life requires fluidity of identity with satisfaction of 'who we are' emanating from what is being done at the moment, or what is being planned to be done in the future but not merely on what has been done. In view of this, the concept of identity is a very fuzzy one that is dynamic but not static. As we grow and develop in our daily lives, so does our identities. This study aims to bring out the flirtatious nature of identity. The data for the study was gathered from birthday messages that were sent to me. These messages left me wondering 'who am l' really. In an attempt to analyse the different messages, I came to realise the fluid nature of identity, the rationale for this paper. The main findings of the paper suggest that the 'self' is ever changing over time.

\section{Introduction and Background}

The social media can be an interesting place to seek answers for who we are. It is one of the places that can open the world for us. In such a space, one gets in contact with people you know, lost acquaintances, people you come in contact with among many other relations. Based on the above, the concept of identity appears to be a fuzzy one which then makes it difficult to say what it is. This is because there appears to be no such thing as identity as there is continuous negotiation and renegotiation from birth to death (Foncha 2013). This study is based on how identity is construed to an individual.

When we grow up, we have many stages that we go through to become who with are. This can be affirmed by the continuous movement that undertake from place. Whenever we migrate, we come into contact with different people and may forget some of these people as we create new acquaintances. Some of these acquaintances are carried out throughout our life spans and some are forget. Some of them are memorable and others opaque. In view of the above, the study strives to see how identity is constructed and apportioned to individuals.

\section{Aims and Objectives}

The aim of this study is to ascertain the way that identity is ascribed to individuals. The main objectives would be the reasons for such associations and their differing nature.

Research Question: Who am I on Face book?

\section{Literature Review}

CDA as a school or paradigm is characterised by a number of principles and thus can necessarily be interdisciplinary and eclectic. Moreover, CDA is characterised by the common interests in de-mystifying ideologies and power through the systematic investigation of semiotic data (written, spoken or visual). CDA also attempts to make their own positions and interests explicit while they still struggle to retain their respective scientific methodologies and to remain self-reflective of their own research process.

From a contextual perspective, CDA can be seen as "a theory and method analysing the way that individuals and institutions use language" (Jameson 2007: 1). Critical Discourse analysts focus on "relations between discourse, power, dominance and social inequality" (van Dijk 1986:249) and discourse (re)produces and maintains these relations of dominance and equality". Because of their concern with the analysis of the "often opaque relationships" between discourse practices and wider social and cultural structures, CDA practitioners take an "explicit socio-political stance" (van Dijk 1997:249). CDA is then seen as a type of discourse analytical research that primarily study the way social 
power abuse, dominance and inequality might be enacted, reproduced, and resisted by text and talk in the social and political context. Critical discourse analysts also take explicit position and thus they want to understand, expose and ultimately resist social inequality (van Dijk 1998:352). Thus a shift from one language or construct to another should not be on the basis of which language/construction is considered more powerful than the other but rather on the purpose of the unification of diversity and languages which is the case in the construction of individual, national and cultural identities, the rationale for this study. CDA in this regard seems to place particular emphasis on the interdisciplinary study of discourse, that could be mediating between the linguistic and the social and regarding the social more than a mere contextual backdrop to the texts (Weiss and Wodak 2003). CDA seems to address broader social issues and also may attend to external factors, including ideology, power, inequality, etc., and could possibly draw on social and philosophical theory to analyse and interpret written and spoken texts (Fairclough 2003).

\section{Identity and Culture}

Social media is a special space of its own where many people are allowed into the lives of others. In view of this, Fairclogh's (2003) notion of the Social Constructionist theory which legitimises and distributes identities to individuals and groups becomes very important. In order for us to get a better understanding of how these identities are associated to individuals, it is needful to know what culture does to these individuals and how they see the world around them. Hall describes culture as an "unseen but powerful force that holds everyone captive: "Culture is not an exotic notion studied by a selected group ... It is a mould in which we all are cast, and it controls our lives in many unsuspected ways" (1959:52). He further states that "culture hides much more than it reveals, and ... it hides [itself] most effectively from its own participants" (Hall 1959:53). His argument suggests that the individuals that are caught in this web of culture do not realise their entanglement since attitudes and behaviours are usually being shaped by cultures. From another perspective, Varner and Beamer (2005:5) define culture as "the coherent, learned, shared view of a group of people about life's concerns that ranks what is important, furnishes attitudes about what things are appropriate, and dictates behavior". Therefore we as humans are capable of changing for better or worse. All this is to suggest the different subjective worldviews of individuals and groups. As such, it is indicative of the different constructions that we as individuals have towards others which is the rationale for this study.

To clarify it further, it is needful for this writer to point out that culture uses language to construct and ascribe identity to individuals. In this regard, language constructs culture and is in turn constructed by culture.

Identity and culture in this study is constructed through discourse and this can explain why the notion of identity is a very porous concept that can only be understood within a given context through an ethnographic study because it appears to mean different things to different people. It might be useful for the purpose of this study to look at personal identity, cultural identity and social identity. These different forms of identities might have been created by the different contexts of interactions that can be referred to as culture. They appear to be very confusing to our understanding, as well as in practice by the participants in this research.

Identity can be seen as socially constructed, something we "do" rather than something we "are" (Ochs 1993). We "do" different identities in different context and therefore we have multiple rather than a single identity. Identity therefore should be regarded as a cover word for a range of personae, including statuses, roles, positions, relations, institutional and other relevant community identity that one may attempt to claim or assign in the course of social life (Ochs 1993:288). Identity is also constituted in our discourses through our conscious and unconscious thoughts and emotions where our sense of the self are constantly reconstituted in discourse each time that we speak or think (Weedon 1987:32). Individuals are known to negotiate their identities with others in order to attain interactions. In light of this, I argue that it is not sufficient for an individual to look at the self as constituting a particular identity; others must also recognize the identity as well. Individuals are capable of taking up or resisting identities that may be assigned to them.

\section{Cultural Identity}

For the purpose of this study one needs a stronger focus on the understanding of the "self" first and foremost before an understanding of "other". This means that cultural identity appears to be an individual's sense of the self that must have been derived from formal or informal membership in groups that might have transmitted and inculcated knowledge, beliefs, values, attitudes, traditions, and ways of life (Jameson 2007). Thus a study of "other" is a study of "self" in relation to the "other". A broad conception of cultural identity should not privilege nationality but instead should try to balance components related to vocation, class, geography, philosophy, language, and the social aspects of biology. Cultural identity can change over time mainly through negotiation and renegotiation. It can be intertwined with power and privilege 
that might have been affected by close relationships, and negotiated through communication. The proposed model of cultural identity can serve to highlight components that are directly related to intercultural communication competence, such as language, economic class and professional affiliation, and can also demonstrate how culture does not only connect people but also appears to define them as unique individuals (Jameson 2007). This model can enrich learning in interculturally diverse communities. Through the above lenses, Cultural identity should therefore be seen as one part of a larger concept of individual identity.

\section{Postructuralist View of Identity}

The poststructuralists view identity as the recognition of the processes of restriction. In view of this, there is a call for theoretical framework that should understand social identities and the self as social, historical, multiple and evolving within the context of power relations. This view of identity seeks to make possible the recognition of experiential multiplicity. It further challenges the ability to know or understand anything directly or absolutely which in effect re-echoes the dynamic nature of identity. In this regard, the truth should therefore be seen as subjectively mediated by discourse, power and desire Hames-Gracia 2003). This is meant to suggest that the subject in search of liberation "turns out to be discursively constituted by the very political system that is supposed to facilitate its emancipation" (Butler 1993:213).

The poststructuralists further claim that because of the subjectively mediated nature of knowledge and experience, normative judgments are always subjective and contingent, if not arbitrary. In view of this, there cannot be a reliable justification for any identity ascription to any individual. Resistance of identity from this stance or perspective can only either reverse the flow of power or dismantle it in a way that something new might take their place (Foucault 1979).

Identity is never stable or internally homogenous (Foncha 2013). This is to suggest that we are not born with any given identity but rather we pick up baggage of identity as we grow. In the same way we pick up these identities, we also drop some of it to develop new ones. Thus identity is not static but dynamic. Foncha (2013) further argues that an identity that is accepted joyfully at one point may be resisted by the same individual the next moment. In view of this, some identities have a life span and when this is exceeded, it can create problems between an individual versus others. Therefore, there cannot be any such thing as authentic or exemplary identity which creates an epistemological difficulty for the concept of identity. That is to say that we cannot know with certainty what criteria to apply in analyzing and understanding the identity of an individual or a group.

Based on this, there is the risk of naturalizing some traits or experience as normative and thereby marginalizing others. Thus it is engaging in the practice of ideological normalization and exclusion. When people change their class, status, age etc they also tend to view themselves based on their present identity and may take offense in a situation where they are reminded their previous identity. Society on these bases needs to be on the guard to update individual identity since it is a fuzzy concept.

The bitter truth is that in a racist society where a brown skin (along with others colors) can cost lives, people will embrace any ideology that seems to offer hope for change. Even when that ideology proves to be counter-productive, the hope persists... [Nationalism] then has to be seen as a complicated two way edge sword. It can't be fully understood if we just dismiss it as 'identity politics'" (Moya 2003:1). Thus, identity can be said to be responsible for intellectual, physical, moral, educational and all other forms of fighting in the society.

\section{Critical Discourse Analysis (CDA)}

In order to understand how identity is constructed, it is necessary for this writer to look at Critical Discourse Analysis because it through it that identity is constructed and ascribed to individuals and groups. The analysis of discourse is necessarily the analysis of language in use. As such, it is not restricted to the description of linguistic forms independent of the purposes or functions which these forms might have been designed to serve in human affairs (Brown and Yule 1983:1) Discourse is therefore a culturally and socially organised way of speaking where the context of interaction becomes the key to meaning making.

In view of the above, language is used to "mean something and to do something" and that this "meaning and doing" are linked to the context of its use (Talbot 2007). Therefore for one to interpret a text properly, "one needs to work out what a speaker or a writer is doing through discourse and how this 'doing' can be linked to wider inter-personal, institutional, socio-cultural arm of social practice material contexts". "Texts" in this respect refers to "the observable product of interaction," whereas discourse is "the process of interaction itself: a cultural activity" (Talbot 2007:9).

This view of language as action and social behaviour as emphasized in CDA sees discourse - the use of language in speech and writing - as a form of social practice. It is this definition of discourse as a social practice that is most useful 
for the analysis of discursive construction, since it involves a two-way relationship between a "discursive event" (i.e. any use of discourse) and the situation, institution and social structure in which it may occur: discourse can be shaped by these but it also can shape them (Fairclough 1992:62). In other words, language represents and contributes to the (re)production of social reality. This definition of discourse establishes a link to identity ascription as engaged in "reality construction". Foucault does not think of discourse as a piece of text, but rather as "practices that systematically form the objects of which they speak" (Foucault 1981: 49).

By discourse, Foucault means "a group of statements which can provide a language for talking about - a way of representing the knowledge about - a particular topic at a particular historical moment" (Hall 2000: 291). Discourse as Foucault further argues governs the way that a topic is meaningfully talked about. It also influences how ideas are put into practice and it is also used to regulate the conduct of others. This means that discourse (or discourses in the social theoretical sense) limits and restricts other ways of talking and producing knowledge about the construction and ascription of identity.

According to Fairclough (2003) languages are appropriated to legitimise, negotiate and challenge particular identities. Through discourses, humans from different cultural and linguistic backgrounds are able to negotiate their biases with each other in order to construe identities to self and other. In view of this, the "self" and "other" are at the fore and there is need for some form of compromise through negotiation and renegotiation to be able to reduce the tension that exists between the two.

Based on the above, corson argues that:

The life chances of students are determined by their ability to interact critically with the discourses around them, while still avoiding the temptation to be seduced by the disempowering messages those discourses often contain. The discourse surrounding children teaches them who they are, what their place is in the world and what they need to do to become autonomous and valuable citizens. Language, critically acquired, is potentially empowering for people as they constantly build on previous encounters with the words in their unique search for meaning and value (2001: 14).

The above quotation is also echoed in Foncha (2013) when he notes that the concept of socialization is very vital in participants' understanding of discourses around and within them. Thus these participants need to be culturally sensitive and affective in order to negotiate and renegotiate their identities as it is an unending process. The more a participant understands the world view that a given space provides to him/her, the easier it is for that participant to negotiate his/her identity. Interaction therefore is known to be a vital ingredient through which identity is constructed and construed to individuals.

\section{Methodological Considerations}

This paper is based on messages that were sent to me during my birthday in which case I tried to question who I am for sure. These messages provoked many questions of identity in my life and I began to wonder what such a concept really is.

According to Rapport (1999) narratives may be understood as defining the stories people tell about themselves and their worlds. As such they propagate a meaningful sequence across time and space. In Rapport's opinion narratives embody a perceived routine, and in their telling they maintain this routine despite temporal, spatial and experiential disjuncture. In a world of motion, these can be said to provide the world traveler, be it the anthropologist or the subject under study, "a place cognitively to reside and make sense, a place to continue to be" (1999: 10).

A functional life-story is one that can address the issue of personal identity by describing how a person has come to be the current self via the remembering and interpretation of past experiences, with this idea being endorsed (Karniol and Ross 1996). Individuals often react to the present as if they were reliving the past. The past, as represented in people's memories and in their conceptions of history, can also be said to influence motivation.

The stories that people construct about their lives can possibly be influenced by how they see themselves at a particular time. In this sense, identity should then be seen as a life story (Whitty 2002). Narrative and self are said to be inseparable in that the former is borne out of experience while it gives shape to experience. Narrative in this sense should be considered as a version of reality, and as such an essential resource in the struggle to bring experiences to conscious awareness (Ochs and Capps 1996).

Karniol and Ross (1996: 593) are also of the opinion that in order for one to examine conceptions of the future it is important to determine how the individuals in question 'bridge' the present and the future. It would appear as if the past is central to their argument in that it can be a view of the past that people tend to project to certain future goals and which is 
a common occurrence in an ethnographic study. In this regard, the concept of the 'motivational push' of the past captures the significant impact that this aspect has on an individual's life. They investigate the impact of current goals on recall, as well as individual differences in using the past. It is specifically these aspects that resonate with the current study being carried out. In this regard, an individual's story needs to be seen as a subjective construction of episodes filtered by the narrator's perception and understanding of relevance of those events, activities and decisions mentioned. Telling the story therefore may imply giving sense to a number of single stories that are temporally and/or causally connected, by integrating them into the large context.

According to Kehily (1995) the process of story-telling has been known to be further influenced by the audience (among other factors). If it can be reflected upon carefully it should rather be used as an educative process, as it appears to reveal the influence of the past on the present. By analyzing the content and style of a story therefore, analysts might be enabled to discuss its topics and underlying themes of how they are influenced by the discourse and the genre (Hallden 1999). Narratives have been found to be a primary embodiment of our understanding of the world, of experience and ultimately ourselves. In this sense, a narrative should yield a form of understanding of human experience, both individual and collective, that cannot be directly amenable to other forms of exposition or analysis.

Whitty (2002) also suggests that when an identity is to be conceptualized as a life story, research should also consider story-writing methods in their investigations into identity-formation. To know a person therefore, according to Whitty, is to know the story in which that person might have been participating in. In view of this, making sense of others requires knowing their subjective experience as people are said to live in and through their stories. What this implies is that identity can be a life story (Whitty 2002). It appears to me that this combination of features of the life-history, alternatively referred to here as a 'narrative', can become a suitable investigative tool for a study of this nature.

Thus the use of the Qualitative research method is deemed necessary for this study because it can provide a better understanding of the phenomenon through the use of critical Discourse Analysis. The data for this study was collected from birthday messages from my face book account. I wish to use the interpretive paradigm as my unit of analysis where I wish to recapture my life story as a narrative.

\section{Data Analysis and Discussion}

I propose to build up a chain of narratives and interpretations in this section. It presupposes a construction of a story of their story where my narrative should be seen as an interpretation of their interpretations of my identity. In order to achieve this task, I need to reinforce my beliefs that underlie this study and interpret the findings in terms of lived through experience. I focused on the role of interpreting the interpretations of my participants which signified a perspective of unrest and underlined my attempt to raise my thinking and practice to a higher level of understanding through interpretation. In view of this unrest, I now understand how my stance positions itself against a positivist view based on my acceptance of the context of this research as a means of constructing and interpreting knowledge. In this regard, I have used my research method to contextualize and re-contextualize the question of this investigation (Toulmin 1990). For the interest of clarity, I have discussed the following issues in order to reinforce my research perspective: the problem of objectivity, rejection of objectivity, rejection of interventionist approaches and thereby reinforcing "re-telling as a way of experiencing the experience" (Sivasubramaniam 2004:356). This, I wish to point out as the rationale for the discussion of findings.

For the purpose of this study, I found it necessary to look at objectivity and subjectivity in this study though they are intricately connected. Analysis involves the search for patterns or significances in data within the context of the research situation. Interpretation involves explaining these patterns or significances within a wider context by applying relevant theory. While analysis questions what the data "says," interpretation on its part questions what it "means." In both cases, the potential for objectivity depends on the subject-researcher interaction. Although similar factors are involved at the two levels, the difference is critical.

Below are some of the messages downloaded from my face book account that have to do with my membership to respective groups where I was a member or still is a member:

Participant A: Brother John, may the almighty God help you to attain your full destiny, may he shower you with more birthdays and the wisdom of King Solomon.

Participant B: As a Folonist, may you grow to the peak of knowledge

Participant C: Presi, May the good lord give you many more birthdays

The data above came from three different groups and with each member ascribing an identity that has to do with 
group membership.

In massage A, the Participant was a member of a church fellowship where we referred to one another as brother or sister in Christ. Brother here is not biological and is construed only to the members who fellowship together and since then, I am known to this participant as brother.

In passage $B$, the participant is a long time acquaintance way back in the early nineties when we were studying together for our under-graduate Degree. We had a discussion group that was known as the Benard Fonlon association and we called our group members Fonlonist. In view of this the participant urges me to grow to the peak of knowledge because that was our focus as group members. Secondly, I was in the final phase of my Ph.D.

The third participant is a follow Cameroon and member of ECACSA (Eastern Cape Association of Cameroonians in South Africa where I am the president.

The three messages attribute different identities to the same person with the $A$ and $B$ identities being opaque. In light of this, Foncha (2013) argues that cultural identity can change over time depending on the world view of the individual that such an identity is ascribed to. In view of this, as new identities are taken by an individual, some of the old ones are dropped or being resisted. The writer at this juncture would like to see others using his name as an academic to form their own identity rather to be ascribed to an association like the one he belonged to in the nineties.

Based on the above, one can argue that "Membership in various social groups combine with and mutually constitute one another" (Hames-Garcia 2003:103). That is to say that membership in one group might mean something different in a simultaneous group membership, e.g Dr. Dadisco. This is the name that my closest friends call me in some of the messages on my face book wall. This coinage comes from the modification of 'daddy' as my kids refer to me.

In view of this, the totality of this relation in their mutual constitution comprises the self (Hames-Garcia 2003:103). Thus the whole self cannot be understood by its discrete parts but rather by the mutual interaction and relations of its parts to one another.

The study pointed to the direction that all knowledge is perspectival and has led to the understanding that it falls within the ethical practice of ethnography. The constructivist approach to understanding seen in the literature review and methodology, suggests that the study should relive and retell the stories and experiences of the participants' notions as a way of experiencing their experience.

In another perspective, Hames-Gracia (2003) argues that the different categories of social identity do not comprise essentially separate 'axes' that occasionally 'intersect'. On the contrary they blend constantly and differently. They expand one another and mutually constitute one each others' meaning. This is therefore meant to suggest that the subjective experience of any social group membership depends fundamentally on relations to membership in other groups. On my birthday, there were messages to 'daddy', 'Doc', 'pa', 'uncle' etc.

Although identity is understood as multitude through mutuality of the self, there can be some obscurity through domination to which the self can be subjected. By the same token, identity can then be reduced to be understood exclusively in terms of that aspect of the self with the most political salience. E.g. 'Doc', 'Daddy', 'president' etc. Said differently, this is meant to suggest that the self is dominantly only understood in terms of the most dominant construct of identity. In my workplace, very few people know me by name and even my closest friends still call me Doctor. My wife refer to me as 'honey' on face book but 'daddy' at home.

It is worthy of note that some forms of identities can be opaque and as such could turn to down play the politically salient identity in one way or the other. E.g. when I was a member of a Pentecostal church, people did not longer see me as a Doctor but rather as a 'born again'. Even when I was the president of my association, I was now seen as presi or president and not longer 'Doc' or 'pa' etc. This is to say that the self is best understood in terms of the most dominant construct of identity. In some cases, people may tend to see one as frustrated and which could restrict the kind of respect such a person could command in an alternative membership group. Ironically, even if a member is defaulting from his/her group membership, communities could include that member again only if he/she has something to benefit that community. Usually, the effect of a restriction on a certain character is meant to make such a person to feel as an outsider in that given community. The intention behind such a move by the community might be to get the member in question to abide once more to the norms, values and beliefs of the group. Based on this, this paper argues that individuals need to see their own interest, their own people and their own family as extending beyond their immediate group identification. Such a conceptualization needs to see the self beyond their experiences and beyond their immediate group. Makwerikweri identity (xenophobia) can be frustrating although people often time pretend to include.

One should be mindful of the positivist notion of multiple identity which views social identity as a relationship between things that do not have one aspect in common but bear various different kinds of similarities and resemblances. In light of this, multiplicity of identity needs to be seen as dynamism of a social identity. That is to say that identity is fluid and needs constant revision, transformation, adoption etc. 
It is in the light of the poststructuralists that one can challenge the ability to know or understand anything directly or absolutely. Based on this, Hames-Gracia (2003) states that the truth is usually subjectively mediated by discourse,, power and desire.

\section{Conclusion}

Staying the same without change is the reverse of growth. To develop in one's life requires fluidity of identity with satisfaction of who we are emanating from what is being done at the moment, or what is being planned to do in the future but not merely on what has been done. In this regard, steadfast adherence to a given identity should be seen as cowardice. It is worthy of note that evolving from one identity to another requires a lot of emotional and psychological torture together with a lot of energy exhaustion. Therefore, individuals need to make decisions, though imperfect to improve upon when possible but not to hang only on the fantasy of the past. In order words, individuals need to look past what is said to find out what is really going on.

In view of this, fluid identity is "having a sense of self, but a sense of self that may be flexing or changing over time." Identity is something that is contextual and sometimes situational; it is rooted in the experience and stories of self. Many factors can influence identity, including personal, cultural, political and economic agencies. Fluidity of identity should be seen as a sign of integrity because the expressions of one's values evolve. Thus, the question of "who am I" calls for a journey of discovering the self. The self is known to be rooted in the DNA, environment and personal experiences of any given individual that helps to shape identity throughout that individual's life. In this regard, identity has to couple with a few values rather than staunch positions on issues.

\section{References}

Brown, G. and Yule, G. (1983). Discourse analysis. New York: Cambridge University Press.

Butler, S. (1993). Desire in Ethnography: Discovering meaning in the Social science. In Tamboukou, M. and Ball, S. (eds.) Dangerous Encounters: Genealogy and Ethnography. New York: Peter Lang.

Corson, D. (2001). Language diversity and education. Mahwah, NJ: Lawrence Erlbaum.

Fairclough, N. (1992). Discourses and Social change. Cambridge: Polity Press.

Fairclough, N. (2003). Analysing discourse: Textual analysis for social research. New York: Routledge.

Foncha, J. W. (2013). A Selective Investigation of the University of the Western Cape's Students and teachers attempts at Intercultural Communication: Exploring the connections between Intercultural Communication Competence and Identity Construction. University of Western Cape: PhD thesis; Unpublished.

Foucault, M. (1989). The birth of the clinic: An archaeology of medical perception. London: Routledge .

Hall, J. K. (2000). Acquiring Intercultural Communicative Competence from Textbooks. Leuven, Belgium: Leuven University Press.

Hall, E. T. (1959). The silent language. Garden City, NY: Doubleday.

Hallden, G. (1999). 'To be or not to be': Absurd and Humoristic Descriptions as a Strategy to Avoid Idyllic Life Stories... Boys Write About Family Life. Gender and Education 11(4): 469-480.

Hames-Gracia, M. R. (2003). "Who are our people? In Moya, P.M.L. and Hames-Garcia, M.R. (eds.) Reclaiming identity: Realist Theory and the predicament of Post-Modernism. Los Angeles: University of California Press, 102-129.

Jameson, D. A. (2007). Reconceptualizing Cultural Identity and its role in International Business. Journal of Business Communication 44:199-235.

Karniol, R. and Ross, M. (1996). The Motivational Impact of Temporal Focus: Thinking about the Future and the Past. Annual Review of Psychology 47: 593-620.

Kehily, M. J. (1995). Self-narration, Autobiography and Identity Construction. Gender and Education 7: 23-31.

Moya,P. L. M. (2003). Why Identity? In Moya, P.M.L. and Hames-Garcia, M.R. (eds.) Reclaiming identity: Realist Theory and the predicament of Post-Modernism. Los Angeles: University of California Press, 96-101.

Ochs, E. (1993). Constructing Social Identity: a Language socialization perspective. Research on Language and Social Interaction 26:287-306.

Ochs, E. and Capps, L. (1996). Narrating the self. Annual Review of Anthropology. 25 (1): 19-45.

Rapport, N. (1999). The Narrative as Methodology and Ethnomethodology: Individual Belonging in a Post-Cultural World. In: Narrating mobility, boundaries and belonging. Revised papers from the international workshop under the Centre for Development Research (CDR) Programme: Livelihood, Identity and Organization in Situations of Instability (LIVELY). Magleas, Denmark.

Sivasubramaniam, S. (2004). An investigation of L2 students' reading and writing in a literature-based language programme: Growing through responding. PhD Thesis, Unpublished: University of Nottingham, UK.

Talbot, M. (2007). Media Discourse: Representation and Interaction. Edinburgh: Edinburgh University Press.

Toulmin, S. (1990). Cosmopolis: The Hidden Agenda of Modernity. Chicago: The University of Chicago Press. 
Van Dijk (ed.) (1986). Handbook of Discourse Analysis: Volume 4 Discourse Analysis in Society. London, Academic Press.

Van Dijk, T. A. (1997). Discourse Studies: A multidisciplinary Introduction. In Van Dijk, T. A. (ed.) Discourse as Social Interaction. New Delhi: Sage.

Van Dijk, T. A. (1998). A Multidisciplinary Approach. London: Sage.

Varner, I. and Beamer, L. (2005). Intercultural communication in the global. Boston: McGraw Hill//rwin.

Weiss, G. and Wodak, R. (2003).Critical Discourse Analysis: Theory and Interdisciplinarity. In Weiss, G. And Wodak, R. (eds.) Language in Social Life series. Palgrave: Macmillan

Weedon, C. (1987). Feminists Practice and Poststructuralist theory. Oxford: Blackwell.

Whitty, M. (2002). Possible Selves: An exploration of the Utility of a Narrative Approach Identity. International Journal of Theory and Research 2(3): 211-228. 